\title{
Discovering the lived experiences of graduate students in the virtual space: Reflections and lessons from a phenomenological inquiry
}

Ernesto Cordero Collo, Jr.

College of Development Communication,

University of the Philippines Los Baños, Philippines

Email:eccollo@up.edu.ph

\begin{abstract}
The COVID-19 pandemic has radically reshaped the academic life of graduate students and revealed the inequities in the traditional education system in the Philippines. This study is a qualitative navigation of the lived accounts of development communication (devcom) graduate students at the University of the Philippines Los Baños. It foregrounds devcom as a field of theory and practice in honor of its pioneer Professor Emeritus Nora C. Quebral and her contribution to the ferment of the field. The credence of phenomenology informed the direction of this research in addressing a paucity of literature that examines the experiences of graduate students on remote learning within the current milieu. The transition of academia into a new phase of development surfaced stories of personal and academic struggles. As social beings, they engage virtual and real spaces in coping that redirect them to a sense of purpose and semblance of normalcy at a time of uncertainties. To address their recurring and emerging conditions is the cultivation of institutional support and online forms of communication support as two pivotal forms of their reflective recommendations. Drawing from the participants' reflections, I developed a schema that investigates
\end{abstract}


the intersectionality of their struggles, coping, and recommendations towards a conducive remote learning milieu.

Keywords: Phenomenology, Reflective Evaluation, Learning Struggles, Coping Spaces, Reflective Recommendations

\section{INTRODUCTION}

This research was borne out of recurring conversations with fellow graduate students at the University of the Philippines Los Baños (UPLB) since the government-imposed lockdown on March 17, 2020 in response to the surge of coronavirus disease 19 (COVID-19) cases. Our personal struggles as iskolar ng at para sa bayan (scholar of and for the country) in the time of pandemic are evident in these online conversations.

From 187 cases at the start of the lockdown on March 17, cases increased to 3,660 cases on April 6 (Magsambol, 2020), prompting the government to extend the lockdown. While the international community had continued imposing lockdowns and local restrictions for health security, the announcement from our national government still came as a surprise for many sectors and industries in the country.

The Inter-Agency Task Force (IATF) guidelines have been in place in support of the implementation of community quarantine in the Philippines. The IATF generally aims to "facilitate intersectoral collaboration to establish preparedness and ensure efficient government response to assess, monitor, contain, control, and prevent the spread of any potential epidemic in the Philippines" (Executive Order No. 168, s. 2014, as cited in IATF, 2020, p. 1).

With the varying impacts of the COVID-19 pandemic on the environment, local tourism, economy, community-supported agriculture, media, and academia, these communities have learned to embrace practices in futures thinking and foresight.

The COVID-19 pandemic has radically reshaped our academic life as graduate students. The shift to online spaces as a phenomenon has exacerbated previous challenges in our educational system and added more barriers to accessible and equitable education.

Several competing studies delved into some of these barriers brought about by the pandemic. These studies include a quantitative examination of the online experiences of medical students in the Philippines by gauging their access 
to technological resources, living conditions, and perceived barriers (Baticulon et al., 2021) and "the exclusionary potentials of networked learning" which may further perpetuate the existing social inequities (Selwyn, 2010).

Others, however, have explored emerging technologies as opportunities in the time of pandemic to provide mental health support and develop curricula responsive to the felt needs of the students (Toquero, 2020) and a recalibration on the planning and implementation of the new normal educational policy (Tria, 2020).

Restrictions on mobility have affected not only the fields of medical and allied health sciences, but also the arts and social sciences. Pre-pandemic time, the "outside world" used to be our spaces for critical discourse, artistic expression, and development work.

Today, the virtual space has shrunk these spaces into our screens, relegating dialogues into computer screens while blurring our sense of privacy and our concept of home.

Primarily, this phenomenon has exposed the inequities in health systems and the pre-existing gaps and needs of our education system. The pandemic has also interrupted the conventional system of education, predominantly affecting teachers who have transitioned from the physical classroom to the online sphere. The new pedagogical modes of teaching are central to this shift in our educational landscape for which academics were not previously trained.

Camposano (2021, p. 35) expressed the urgency to "(re)introduce issues of inequality and exclusion into the conversation" and the importance of "local contexts in the framing of learning processes and practices." These recommendations allow teachers to reimagine the unique values of Filipino and local pedagogy.

Fabella and Arandia (2021) critically synthesized the challenges confronting private education and their solutions to these issues. Some challenges are reductions in school funding, flexibility in learning, and pivots in marketing.

As a graduate student myself, it is a moral obligation to help create a platform that nurtures and reinvigorates the interplay of reflection-(re)actionreflection especially at this crucial time.

With this intent, we hosted a virtual roundtable titled "Navigating Development Communication Life in the Time of Pandemic and Beyond" on April 20, 2021, in collaboration with the UPLB Graduate School and the College 
of Development Communication. The roundtable generally aimed to support devcom graduate students in navigating their study and practice in the time of pandemic and beyond.

\section{Reintroducing Development Communication}

In 1949, US President Harry Truman proposed the Point Four Program as a policy of economic aid to alleviate human suffering of underdeveloped countries. Emphasis was placed on technical assistance, largely in the fields of public health, education, and agriculture.

From this development thrust, the UPLB "experimented in agricultural communication therefore provided a springboard for the birth of the devcom discipline" (Quebral, 1988, as cited in Manyozo, 2006, p. 85).

In 1971, Dr. Nora C. Quebral, the mother of devcom, articulated the concept of devcom in her seminal paper Development Communication in the Agricultural Context. She defined devcom as "the art and science of human communication applied to the speedy transformation of a country and the mass of its people from poverty to a dynamic state of economic growth that makes possible greater social equality and the larger fulfilment of the human potential."

In the same decade that devcom was conceived, "there had been an attempt, particularly by then Information Minister Gregorio Cendaña, to appropriate development communication as theoretical justification to support Martial Law imposed by then President Ferdinand Marcos from 1972 until his ouster in 1986" (Custodio, 2020, p. 3). This gave rise to the propagandistic misconception among the public and few critics towards our discipline.

In repositioning the discipline, Quebral (2006, p. 102) distinguished devcom from other social sciences by reinforcing that "it is not publicity per se or getting the maximum media exposure...for the sake of image-building" and the purpose is to "stimulate public awareness and understanding of planned change...to create a climate of acceptance."

After four decades of constantly rethinking and contextualizing devcom, Quebral (2012, p. 3) redefined the discipline as "the science of human communication linked to the transitioning of communities from poverty in all its forms to a dynamic state of overall growth that fosters equity and the unfolding of the human potential." 
Based on Quebral's definitions throughout the years, the people are a constant component and subject of development. According to Ongkiko and Flor (1998, p. 132), "development communication entails motivating individuals and groups of people such as farmers, fisherfolk, workers, housewives, and the youth to change their habits, their lifestyles, their way of thinking, their way of doing things."

Since the inception of devcom in the 1970s as a response to the changing dynamics of development, the body of scholarly literature within the field has served as the primary source of government institutions, agencies, and organizations in implementing programs and projects for communities.

Today, devcom is known as a homegrown field of UPLB "by experimenting with method-driven and theory-based extension efforts in using communication to promote sustainable development" (Quebral, 1988, 2002, as cited in Manyozo, 2006, p. 84).

\section{LITERATURE REVIEW}

A phenomenon that changed the face of a generally traditional system of education in the Philippines is the COVID-19 pandemic.

According to UNESCO (Nortajuddin, 2021), as of March 17, 2021, "some 171 million pupils enrolled at pre-primary, primary, lower-secondary, and upper-secondary levels of education and tertiary education have been affected due to school and institution closures." Nortajuddin (2021) added that "Koumba Boly Barry, UN Special Rapporteur on the right education, called it an education crisis."

As early as June 2020, our government officials announced that millions of students will not be returning to physical classrooms until the COVID-19 vaccine is available to the public (Montemayor, 2020; Nortajuddin, 2021; Romero, 2020), which prompted educators "to use distance learning methods via the internet or TV broadcasts where needed" (Nortajuddin, 2021).

In understanding the shift of learning modalities due to the COVID-19 pandemic as a phenomenon, it is important to contextualize it within history. Kuhn (1962) posited that "scientific advancement...is a series of peaceful interludes punctuated by intellectually violent revolutions and in those revolutions, one conceptual world view is replaced by another" leading to a paradigm shift. 
According to Garmer and Firestone (1996, as cited in Librero, 2003), "the paradigm of learning has shifted away from the traditional notion that knowledge is transferred from teacher to student within the confines of the physical classroom."

This paradigm shift in learning has become even more apparent at this time. While universities have been adopting the new learning paradigm since the 2000s, the COVID-19 pandemic forced all learning institutions to embrace this paradigm shift.

Among the earliest phenomenological studies that problematized and assessed the coping experiences of learners during the pandemic focused on international students' narratives (Fura \& Negash, 2020; Kilinc, Arslan, \& Polat, 2020).

With the popularity of qualitative studies among health sciences, a few studies delved into the lived experiences of nursing students and nurses across the globe (Gunawan et al., 2021; Lovric et al., 2020). In the Philippines, Delute and Ada (2021) explored college students' lived experiences during the COVID-19 outbreak lockdown in a phenomenological analysis.

Meanwhile, a quantitative study that provides a broader overview of student experiences has documented "the students' curricular needs, safety and well-being, the efficacy of institutional communications and support" and recommended opportunities that address "gaps in institutional services" and the "delivery of instruction" (Blankstein, Frederick, \& Wolff-Eisenberg, 2020).

According to the University of the Philippines-Padayon Public Service Office, "while many students have their own computers, more than 5,600 UP students are in danger of not being able to continue their education" due to poverty. The UP System has embarked on a Fundraising and Resource Generation Campaign as a means of assistance to disadvantaged students.

Documented in several qualitative studies are parents' experiences and challenges regarding home learning and management at the time COVID-19 pandemic (Bhamani et al., 2020; Weaver \& Swank, 2021).

Unequivocally significant to the teaching-learning process in online education are teachers' stories. Khanal (2020) studied the online teaching experiences of private school teachers by examining how they perceived and adopted technological learning which provided lessons for curriculum and teaching for future application. 
Generally, this systematic review of literature reveals a paucity of literature that analyzes the online experiences of devcom graduate students at any university in the Philippines, given the critical role of the discipline in the realms of theorizing, development, extension, and education.

\section{Emergent Research Questions}

Beyond the idea of facilitating a virtual roundtable and pursuing a research project is the concept of fostering "a community of truth" (Palmer, 1998, p. 95). Palmer expressed that "the hallmark of a community of truth is in its claim that reality is a web of communal relationships, and we can know reality only by being in community with it" (p. 95).

This virtual roundtable served as a point of departure for this qualitative study. The participants shared their reflective accounts based on the roundtable and the conversations that followed thereafter.

The general objective of this research project is to understand these accounts of devcom graduate students through the rigors of a phenomenological inquiry. To thread these experiences, I attempted to analyze the stories of struggles of devcom graduate students in the time of pandemic; to determine their coping strategies; and to develop a schema that integrates their learning struggles, coping, and reflective recommendations.

\section{METHODS}

\section{Conceptual and Methodological Foundations}

Communicationally, the socio-cultural tradition helped me traverse my entire process of examining the online experiences of the participants. Craig (1999, p. 144) defined this tradition as "the discovery of communication, largely since the $19^{\text {th }}$ century and partly under the influence of semiotic thought, within the intellectual traditions of sociology and anthropology."

In this terrain, researchers, scholars, and students problematize the "gaps across space (sociocultural diversity and relativity) and across time (sociocultural change)" which prevent us from interacting as caused by the lack of "shared patterns on which interaction depends" (Craig, 1999, p. 145).

This study highlights the sociocultural change or the apparent shift in academic interactions due to COVID-19 brought about by the breakdown of traditional social orders in conducting graduate studies. 
Craig $(2016$, p. 6) proffered that the communication problems of the socio-cultural tradition are "collaboration and organization, social conflict and change, communication across cultural differences, and the quest for community in diverse, multicultural societies."

In this research, I strived to understand the reflective accounts of devcom graduate students by analyzing their stories of struggles and coping strategies in the time of pandemic. Eventually, I realized that I was leading towards adopting phenomenology as my methodology in analyzing their learning realities and in forwarding ground-up solutions anchored on their lived experiences.

According to Creswell (2007, p. 57), a phenomenological undertaking "describes the meaning for several individuals of their lived experiences of a concept or a phenomenon." As both a methodology and a philosophy, this qualitative approach enables researchers to collect data "from persons who have experienced the phenomenon" and to develop "description(s) of the essence of the experience for all the individuals" (Moustakas, 1994, as cited in Creswell, 2007).

Theorized as a dialogue or experience of otherness, phenomenology is mainly a $20^{\text {th }}$ century tradition traced from the pioneering work of Edmund Husserl and other hermeneutic phenomenologists such as Martin Buber, HansGeorge Gadamer, and Carl Rogers (Craig, 1999).

Phenomenology appeals to the commonplace beliefs that human beings are capable of treating others as persons (I-Thou) and not as objects (I-It) and that differences are important in seeking a common ground for an experience (Craig, 1999).

\section{Methods, Co-participants, and Analysis}

Scholars have long introduced online methodologies even before the pandemic. Hewson (2010, as cited in Salmons, 2015) forwarded the term Internet-mediated research (IMR) which is "used to gather original data via the Internet with the intention of subjecting them to analysis to provide new evidence in relation to a specific research question." With issues in mobility, "distance turn-digital" methods (Luton, 2020) guided me in navigating stories of struggles and coping.

Fifteen (15) participants during the virtual roundtable titled "Navigating Devcom Life in the Time of Pandemic and Beyond" held via Zoom on April 20, 2021 served as research participants by engaging in a reflective evaluation. All 
of them are taking $\mathrm{MS} / \mathrm{PhD}$ in Development Communication as their major or cognate program.

As commonly practiced, evaluation forms usually assess academic fora and conferences, but a reflective evaluation adapted for this research delved deeper into the personal reflections of the participants.

Eventually, I reached out to them and examined further facets of remote learning that shaped the direction of this study. In doing so, I engaged in conversations via Messenger, SMS (short message service), and e-mail.

Central to the process of coding, analysis, and writing in a qualitative inquiry is analytic memo writing. According to Saldaña (2009, p. 32), "the purpose of analytic memo writing is to document and reflect on your coding process and code choices, how the process of inquiry is taking shape, and the emergent patterns, categories and subcategories, themes, and concepts in your data."

\section{RESULTS AND DISCUSSION}

The results and discussion of this study follow Wolcott's (1994, as cited in Saldaña, 2011) three dimensions of qualitative research as writing style and structure: (1) description; (2) analysis; and (3) interpretation.

The data presented in this portion of the study are exemplars from the participants' reflective accounts on remote learning. Fragments of my personal reflections and musings were also seamlessly integrated into the discussion to assert my active participation in the study.

\section{Stories of Struggles}

\section{Theme: Learning Struggles in the Virtual Space}

The pandemic has prompted communities to transition into a new phase of development and a complex web of events within the current social milieu. In the Philippines, academic institutions as systems often confront changes with acceptance or resistance.

Devcom as a field of theory and practice is essentially contingent on interpersonal dialogues, field immersions, and communication planning. Educational institutions and fields had to revisit their practices, systems, and pedagogies to genuinely address the needs and conditions of learners. 
While the adoption of remote learning to reach out to students during this crisis has been prevalent in every corner of the globe which is found to be more sustained and effective at the higher education level (Bao, 2020; Johnson, Veletsianos, \& Seaman, 2020, as cited in Khanal, 2020).

Before this pandemic hit almost every facet of human life, devcom students had always been passionate about doing development work by visiting affected areas wreaked by typhoons and other natural calamities in eastern and northern Philippines. We used to convene in a cafeteria or a lecture hall for discursive conversations and productive conferences with fellow students and researchers.

Today, we have an all-new way of thinking, doing, and becoming. We have relegated our manner of pakikipamuhay (immersion) and authentic dialoguing to our computer and phone screens via Zoom and other platforms.

As we continue to thread learning in this critical time, stories of struggles (and even of silence) from the lens of graduate students should be truthfully told and understood. Initially, their accounts were categorized as (a) personal struggle, but with iterative coding, (b) academic struggles also emerged as another category.

\section{Personal Struggles}

Constituting our personal struggles are two subcategories-(a) structural struggles and (b) emotional struggles-that directly affect our learning climate in this time of pandemic.

In terms of structural struggles, internet connectivity issues have become a source of anxiety among students in all levels. In this time of global health crisis, internet access has proven its place across the globe to be a fundamental right. It is both an issue of infrastructure and structure caused by capitalism and competition among internet providers.

In the Philippines, the leading internet providers have announced connectivity issues on several occasions, causing class disruptions and suspensions. "The country ranked $83^{\text {rd }}$ out of 140 countries based on its mobile internet speed last month, up by three spots from its previous rank" and "at the sixth spot for mobile and broadband speeds among the ten ASEAN countries" (CNN Philippines, 2021).

Emotional struggles, on the other hand, are also equally valid forms of personal struggles. Mental health issues and the feeling of isolation emerged 
as concerns that may have been caused by the sudden shift of our learning paradigm-from classroom to virtual learning, from physical to mediated learning, from real to imagined learning.

Based on the reflection of Loida and a few others, the feeling of frustration is more than real, affecting their well-being. Loida held,

"With the online modality, there are no physical interactions between students and teachers. This often results in a sense of isolation for the students."

\section{Academic Struggles}

To keep up with the changes of the times, private universities, state universities and colleges (SUCs), and the UP System have begun shedding out their traditional skin in terms of learning paradigms. For the longest time, we are finally embracing systems and futures thinking that address the longstanding educational inequities caused by neoliberalist thinking and practices.

Some of the pressing academic struggles of devcom graduate students include (1) bridging old and new classrooms, (2) limited mentor-mentee relationship, (3) virtual vs real development work, and (4) slow document submission system. These struggles represent the rough road towards educational reform that contends with the gaps and issues in our systems.

For Emy, Cecille, and a few others, the shift in the learning environment and climate is an interminable challenge confronting them.

"It's the warmth of the old classroom interaction that's missing."

"As a traditional learner who prefers to flip books rather than browse and scroll an e-book, I find it hard to study using a gadget."

This reflection springs from the abrupt and total transition of academic institutions from face-to-face, interpersonal classes into remote, technologymediated learning. Pre-pandemic time, we could freely visit the university and local libraries; attend campus seminars for free lectures, peer-to-peer conversations, and free coffee; and physically participate in weekly classes and roam around the campus.

In retrospect, some faculty members for the last two semesters of remote learning have facilitated synchronous classes with at least one UP System-wide reading break for each semester. They have also produced weekly learning modules for asynchronous learning that may replace or supplement synchronous 
classes. Given these compassionate adjustments, many of us still yearn for the warmth of physical spaces as classrooms.

With immediate solutions like "supporting the training and development of teachers, addressing issues in internet connectivity...and providing public assistance to those affected economically," institutions are encouraged to regard these challenges as a "call to action and policymaking to mitigate the impacts and costs of education disruption all over the country" (Fabella \& Arandia, 2021, p. 21).

As graduate students, we share the appreciation for the efforts of the College of Development Communication to cultivate an environment for healthy mentor-mentee relationships while encouraging critical discourses. Today, due to the heavier workload of the faculty and the increasing level of anxiety and stress among graduate students, limited mentor-mentee relationships have become an issue for a few participants. Jean expressed,

"I would appreciate if some advisers will make time to talk to their advisees. As a $\mathrm{PhD}$ student, I want to present something concrete to my adviser but there are times I do not know how to proceed and I need someone to talk to, which is more than just receiving e-mails."

In the case of Lito, the issue of mobility is a challenge in doing development work. What used to be a vibrant development work in the mountains of Cordillera or in the Indigenous communities in northern Philippines has been gravely affected by community quarantine, lockdown, and health protocols. Lito said,

"Direct immersion to different communities is one of the limitations in this online modality and I cannot think how it could be addressed in this time."

Devcom programs can be divided into four main phases: communicationbased assessment (CBA), communication strategy design, implementation, and monitoring and evaluation (M\&E), according to Mefalopulos (2008, p. 83). At present, development organizations may have already embraced a new way of doing development work, but their social processes and practices are still practically contingent on frameworks and models that guided their work prepandemic time.

The Institute for Social Entrepreneurship in Asia (ISEA) organized the immediate responses and innovations of social enterprises (SEs) and resource 
institutions across the country during the pandemic. The report showed an array of opportunities by which relevant institutions and sectors, alongside the private sector and the government, may help towards "inclusive recovery and building back better and fairer" (ISEA, 2021, p. 27).

There continues to be a challenge for the civil society organizations (CSOs) which constitutes the private sector, non-government organizations (NGOs), and other development organizations: to collectively understand the current conditions of various communities that may lead to social theorizing.

\section{Coping Strategies for Holistic Well-being}

\section{Theme: Virtual and Real Spaces in Coping}

As social beings, we look for coping strategies that redirect us to a sense of purpose and focus. With issues in mobility, however, we are confined within our comfort zones-our homes. While this is a common ground that interweaves our stories of coping, we still differ in terms of our means of coping.

Broadly themed as virtual and real spaces in coping are two main categories classifying the participants' coping strategies-(a) online social support and communication and (b) recreational (dis)engagement for holistic well-being. These coping strategies are a close representation and approximation of our everyday, mundane activities in the time of pandemic.

\section{Online Social Support and Communication}

Our recent proclivities to online social support and communication reveal our newfound place: the virtual space. With the pandemic, we have been propelled to transition into the virtual sphere for socialization and support.

While we have long embraced Messenger, WhatsApp, Skype, Viber, and other social media applications, our motivations and reasons for relegating our spaces to these platforms during this time have also changed.

Two years ago, we scheduled meetings at cafés, attended in-person conferences, and engaged in immersive fieldwork. Our current time reveals a different story. The participants' ways of fostering social support and communication are replaced by virtual spaces where they socialize their anxieties through late-night talks, online conversations, and class consultations. Jean, a new faculty in a national university and part-time graduate student, expressed, 
"I love socializing anxieties with friends, consulting with co-faculty. It helps that the college is also nurturing to its staff, especially to the newcomers."

According to the American Psychological Association, anxiety and stress can be alleviated by cultivating "a sense of normalcy and...social networks" (Wiederhold, 2020, p. 197). As reflected in online social support and communication of the research participants, the use of online applications has allowed them to find support and consolation from family and friends-and even from the online space as a newfound source of community.

For Luisa, on the other hand, online social support goes beyond receiving or reciprocating the act of kindness and compassion. In managing her anxiety, she shared:

"Conducting and attending webinars give me a feeling that I'm still doing the same old things that I used to do prior to the pandemic."

\section{Recreational (Dis)Engagement for Holistic Well-being}

Apparent in our current milieu is the intersectionality of our professional, personal, academic, and social lives in our private spaces-bedroom, kitchen, or living room. Living in different conditions and contexts also plays a central role in (dis)engaging in recreational activities.

This category shows the duality of (un)doing things today which may explain the (dis)engagement of some participants from recreational activities. Constituting this category are three interrelated types of well-being: physical well-being, spiritual well-being, and mental well-being.

Limitations on social mobility across all scales-from local and intercontinental tourism to lockdown orders-have caused significant stress to all walks of life (Bao et al., 2020). While allowing more time for at-home activities, the pandemic has also reduced our capacity to cope during a crisis, especially for the "outdoor enthusiast subculture" or those who are dependent on outdoor recreation as a means of leisure (Rice et al., 2020).

For most participants, recreation for holistic well-being is an integral component of surviving the pandemic and comes in different forms. What practically helped some graduate students in ensuring their physical well-being are biking and virtual exercising which may seem mundane or superficial for others. 
In terms of the spiritual well-being of other participants, they nourish their spirituality through online fellowships with close friends and regular praying sessions with family members. Based on online observations, these participants also regularly post inspirational Bible reflections via Facebook or Instagram as their means of taking things lightly despite their current situations and circumstances.

In terms of taking care or maintaining their mental well-being, Cecille remains "motivated and focused" by "enjoying quality time with family." Meanwhile, for Loida's well-being,

"My coping and recreational activities are spending time with family/ children, taking trips to the countryside, watching feel good and motivational videos."

Other recreational activities of the participants include baking pastries, reading manga, gardening, and planting (hence the term plantito/plantita to refer to plant lovers), online shopping, and leisure reading. A popular streaming service with more than 214M subscribers in 2021 (Stoll, 2021), Netflix has also become an entertainment platform among graduate students.

Morse et al. (2021) argued that previous research has shown the benefits of physical activities for well-being during the pandemic, but less attention has been given to the advantages of creative pursuits. In the case of the UP System and other state universities in the Philippines, immersive webinars and training on music, arts, humanities, and the social sciences have been held to revitalize these areas of human life amid science-driven information in the time of pandemic.

Meanwhile, while others can spare time for leisure and fun, some graduate students cannot privilege self-care and recreation due to personal and practical reasons. Cecille quipped,

"I was not able to delve into any recreational activities. It's not that I don't want to, but I feel that I don't have the luxury of time to do it. I am a mother of two toddlers, working full time and a part-time student. I am occupied with many responsibilities and tasks on hand."

Among all the forms constituting our holistic well-being, our emotions may be the most vulnerable. Gilbert (2001a, as cited in MacDonald, 2012) expressed that "the fundamental aspect of our humanness is our capacity to feel and to show emotion." 


\section{Reflective Recommendations}

With the participants' lived accounts on remote learning during the pandemic, they also posed some reflective recommendations corresponding with the two categories of learning struggles-institutional support for personal struggles and online forms of communication and support for academic struggles.

\section{Institutional Support}

Institutional support, based on the participants' reflective accounts, may come in two significant ways-academic ease and mental support-as solutions to our academic struggles. Emma echoes what many graduate students continue to clamor across social media and virtual conversations,

"The University should extend a helping hand to the students through easing the deadlines and additional mental support."

Since April 2020, the University has released memorandums-advisories, wellness breaks, class suspensions, recovery periods-on several occasions in solidarity with student councils and in response to their peaceful assemblies organized across different UP campuses in the Philippines.

After almost three semesters of remote learning and despite the efforts of the UP System, some participants continue to seek academic ease.

Regarding the demand for mental support, the University has been collaborating with different Colleges and Institutes in conducting webinars, surveys, and other online events for student welfare and development.

Based on a conscious observation, some University webinars at the height of the pandemic in 2020 were esoteric, confined within and exclusive to a few departments, making them inaccessible to other graduate students.

\section{Online Forms of Communication and Support}

The second reflective recommendation of the participants pertains to online forms of communication and support. The virtual roundtable that we hosted has become a safe space among $\mathrm{MS} / \mathrm{PhD}$ in Development Communication students in voicing out their opinions and experiences without reproach. It is also an example of an academic and moral support that encouraged their participation and acknowledged their clamor in this crucial time.

The participants recommended online kapihan (coffee session), Zoomustahan (Zoom catch-up), comprehensive review classes, and virtual socialization, 
among others, as online forms of communication and support. Jean expressed,

"Pag email kasi (If it is email) it is disguised as official. Hindi siya ganoon $k a$-approachable (It is not that approachable). Perhaps online kapihan (coffee session) or brown bag seminar series will help. Also put up a comprehensive review classes or study groups for students who will take it, like a refresher/reviewer course."

In organizing the findings of this study, I developed a schema (see Figure 1) that shows the intersectionality of the participants' learning struggles, coping, and reflective recommendations that have sprung from their intrapersonal dialogue, capturing their self-talk.

The figure shows the COVID-19 pandemic as the precursor of the abrupt transition from physical to remote learning, leading to the accounts of struggles and coping which this study strived to understand.

Generally, these reflective recommendations are the "lessons learned" (Lincoln \& Guba, 1985, as cited in Creswell, 2007) of the participants as graduate students. While the University has been exhaustive in extending academic ease and mental support as forms of institutional support, these recommendations represent our clamor towards compassionate pedagogy and conducive remote learning milieu for all learners.

\section{CONCLUSION}

The COVID-19 pandemic has forced academic institutions to realign their vision and goals to remote learning as a learning paradigm, challenging the traditional education system in the Philippines. As graduate students, our current personal and academic struggles have revealed everything that is inadequate in academia. Graduate education has also been exposed to these inequities exacerbated by the COVID-19 pandemic and poor political leadership.

\section{ACKNOWLEDGMENTS}

This research is in honor of Dr. Nora C. Quebral, the pioneer and mother of development communication-and in recognition of all the efforts of academics, researchers, and practitioners in the field. 


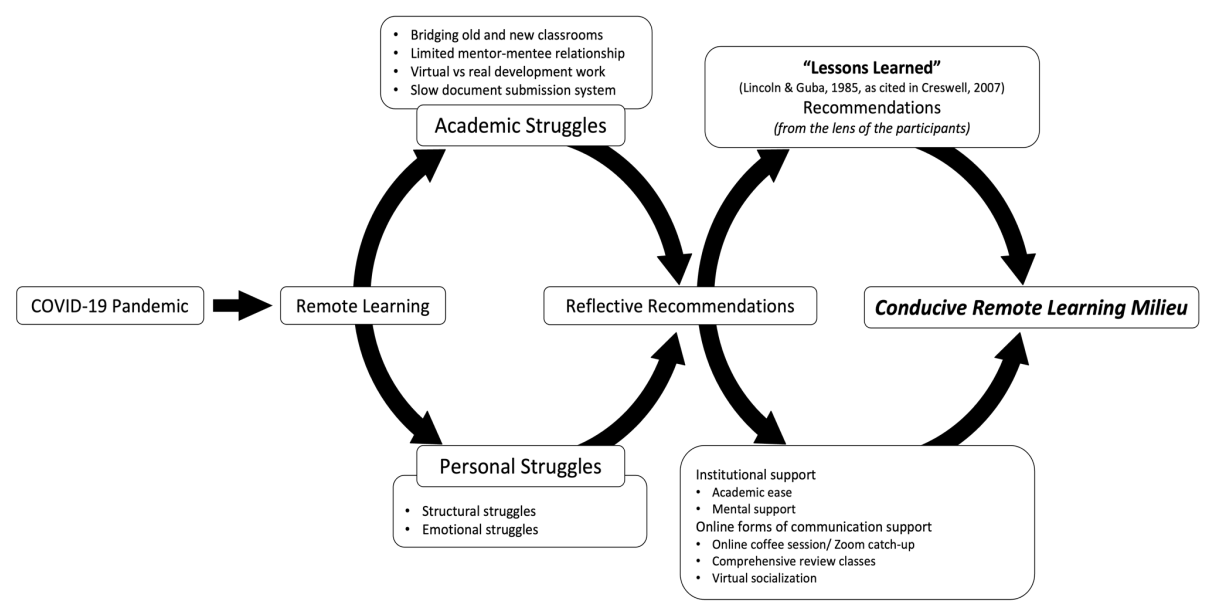

Figure 1. Schema of graduate students' reflective recommendations addressing their struggles towards conducive remote learning milieu

\section{REFERENCES}

Bao, Y., Sun, Y., Meng, S., Shi, J., \& Lu, L. (2020). 2019-nCoV epidemic: Address mental health care to empower society. The Lancet, 395, 37-38. https://www.ncbi.nlm.nih.gov/pmc/articles/PMC7133594/

Baticulon, R., Sy, J., Alberto, N., Baron, M., Mabulay, R., Rizada, L., Chiu, C., Clarion, C., \& Reyes, R. (2021). Barriers to online learning in the time of COVID-19: A national survey of medical students in the Philippines. Medical Science Educator, 31, 615-626.

Bhamani, S., Makhdoom, A.Z., Bharuchi, V., Ali, N., Kaleem, S., \& Ahmed, D. (2020). Home learning in times of COVID: Experiences of parents. Journal of Education and Educational Development, 7(1), 9-26. http:// dx.doi.org/10.22555/joeed.v7i1.3260

Blankstein, M., Frederick, J., \& Wolff-Eisenberg, C. (2020). Student experiences during the pandemic pivot. ITHAKA.

Camposano, C. (2021). The road to sustainable cities (No. 14). The ASEAN.

CNN Philippines. (2021, March 17). PH's mobile, broadband internet speeds rank higher in February. https://www.cnn.ph/news/2021/3/17/PHFebruary-internet-speed-rank.html

Craig, R. (1999). Communication theory as a field. Communication Theory, 9(2), 119-161. https://doi.org/cfzqfe 
Craig, R. (2016). Traditions of communication theory. In K. Jensen \& R. Craig (Eds.), The international encyclopedia of communication theory and philosophy (pp.1-10). John Wiley \& Sons, Inc.

Creswell, J. (2007). Qualitative inquiry and research design: Choosing among five approaches. Sage.

Custodio, A. (2020). Remembering Nora Cruz Quebral (1926-2020) and her devcom legacy. Media Asia, 47(3-4), 174-177. https://doi.org/10.1080/01 296612.2020.1845006

Delute, R. \& Ada, J. (2021). Complying and coping: A phenomenological analysis of the lived experiences of college students studying during the COVID-19 outbreak lockdown. International Journal of Linguistics, Literature and Translation, 4(3), 183-191.

Fabella, V. \& Arandia, A. (2021). Private education during COVID-19: Challenges and solutions. In Paragas, F. (Ed.), Higher education interventions during and beyond the COVID-19 pandemic (pp. 11-21). University of the Philippines Center for Integrative and Development Studies.

Fura, D. \& Negash, S. (2020). A study on the living experiences of people during the COVID-19 pandemic: The case of Wolisso town home-stayed university students. Journal of Psychology Eु Psychotherapy, 10(5), 1-11.

Griffin, E., Ledbetter, A., \& Sparks, G. (2019). A first look at communication theory $\left(10^{\text {th }} \mathrm{ed}\right.$.).

Gunawan, J., Aungsuroch, Y., Marzili, C., Fisher, M.L., Nazliansyah, \& Sukarna, A. (2021). A phenomenological study of the lived experience of nurses in the battle of COVID-19. Elsevier, 1-8. https://doi.org/10.1016/j. outlook.2021.01.020

Institute of Social Entrepreneurship in Asia. (2021). Inclusive and innovative pathways to COVID-19 recovery: Responses and innovations of social enterprises and resource institutions. Oxfam Pilipinas.

Inter-Agency Task Force for the Management of Emerging Infectious Diseases. (2020). Omnibus guidelines on the implementation of community quarantine in the Philippines. https://iatf.doh.gov.ph/wp-content/ uploads/2021/05/20210506-OMNIBUS-RRD.pdf

Khanal, P. (2020). Lived experience of online teaching during the COVID-19 pandemic: Implications for curriculum and teaching. Interdisciplinary Research in Education, 5(1), 89-102. https://doi.org/10.3126/ire. 


\section{v5i1\&2.34738}

Kilinc, A., Arslan, K., \& Polat, M. (2020). Studying abroad: A phenomenological study of lived experiences of international students in Turkey. Journal of International Students, 10(4), 853-871.

Kuhn, T. (1962). The structure of scientific revolutions. The Folio Society.

Librero, F. (2003, April 25). E-learning in a digital world: Issues and directions for Philippine education. [Lecture-discussion]. National Computer Center.

Lovric, R., Farcic, N., Mikšic, S. \& Vcev, A. (2020). Studying during the COVID-19 pandemic: A qualitative inductive content analysis of nursing students' perceptions and experiences. Education Sciences, 10, 1-18. https://doi.org/10.3390/educsci10070188

Lupton, D. (2020, April). Doing fieldwork in a pandemic. (crowd-sourced document). https://schoolforparticipation.files.wordpress.com/2020/04/doingfieldwork-in-a-pandemic.pdf

MacDonald, C. (2012). Understanding participatory action research: A qualitative research methodology option. Canadian Journal of Action Research, 13(2), 34-50.

Magsambol, B. (2020, October 14). Senator Imee Marcos schooled about DevCom after 'cute,' 'archaic' remark. Rappler. https://www.rappler. $\mathrm{com} /$ nation/imee-marcos-schooled-development-communicationremark

Manyozo, L. (2006). Manifesto for development communication: Nora Quebral and the Los Baños school of development communication. Asian Journal of Communication, 16(1), 79-99.

Mefalopulos, J. (2008). Development communication sourcebook: Broadening the boundaries of communication. The International Bank for Reconstruction and Development/The World Bank.

Montemayor, M. (2020, July 27). No face-to-face classes unless COVID-19 vaccine developed: PRRD. Philippine News Agency. https://www.pna.gov. $\mathrm{ph} /$ articles/1110242

Morse, K.F., Fine, P.A., \& Friedlander, K.J. (2021). Creativity and leisure during COVID-19: Examining the relationship between leisure activities, motivations, and psychological well-being. Frontiers in Psychology, 12, 1-22. https://doi.org/10.3389/fpsyg.2021.609967

Nortajuddin, A. (2021, March 17). Philippines: Crisis in education? The ASEAN 
Post. https://theaseanpost.com/article/philippines-crisis-education

Ongkiko I. \& Flor, A. (1998). Introduction to development communication. University of the Philippines Open University.

Palmer, P. J. (1998). The courage to teach: Exploring the inner landscape of a teacher's life. Jossey-Bass.

Quebral, N. (2006). Development communication in the agricultural context (1971, with a new foreword). Asian Journal of Communication, 16(1), 100107.

Quebral, N. (2012). Development communication primer. Southbound.

Rice, W., Mateer, T.J., Reigner, N., Newman, P., Lawhon, B., \& Taff, B.D. (2020). Changes in recreational behaviors of outdoor enthusiasts during the COVID-19 pandemic: Analysis across urban and rural communities. Journal of Urban Ecology, 6(1), 1-7. https://academic.oup.com/jue/ article/6/1/juaa020/5892687

Romero, A. (2020, May 27). Duterte: No vaccine, no face-to-face classes. Philippine Star. https://www.philstar.com/headlines/2020/05/27/2016837/ duterte-no-vaccine-no-face-face-classes

Saldaña, J. (2009). The coding manual for qualitative researchers. SAGE.

Saldaña, J. (2011). Fundamentals of qualitative research. Oxford University Press.

Salmons, J. (2015). Qualitative Online Interviews (2 ${ }^{\text {nd }}$ ed.). Sage.

Selwyn, N. (2010). The 'new' connectivities of digital education. In M. Apple, S. Ball, \& L.A. Gandin (Eds.), The routledge international handbook of the sociology of education (pp. 90-98).

Stoll, J. (2021, November 11). Netflix: Statistics and facts. Statista. https://www. statista.com/topics/842/netflix/\#dossierKeyfigures

Toquero, C. M. (2020). Challenges and opportunities for higher education amid the COVID19 pandemic: The Philippine context. Pedagogical Research, 5(4), 1-5.

Tria, J. (2020). The COVID-19 pandemic through the lens of education in the Philippines: The new normal. International Journal of Pedagogical Development and Lifelong Learning, 1(1).

University of the Philippines-Padayon Public Service Office. (2021). Kaagapay sa Pag-aaral. https://publicservice.up.edu.ph/kaagapay/

Weaver, J. \& Swank, J. (2021). Parents' lived experiences with the COVID-19 
Informasi, Vol. 51. No. 2. (2021), 305-326

pandemic. The Family Journal: Counseling and Therapy for Couples and Families, 29(2), 136-142.

Wiederhold, B. (2020). Using social media to our advantage: Alleviating anxiety during a pandemic. Cyberpsychology, Behavior, and Social Networking, 23(4), 197-198. https://doi.org/10.1089/cyber.2020.29180.bkw 